\title{
ANÁLISE DA GESTÃO PÚBLICA NA ARBORIZAÇÃO URBANA EM MUNICÍPIOS DO ESTADO DE SÃO PAULO
}

\author{
ANALYSIS OF PUBLIC MANAGEMENT IN URBAN AFFORESTATION IN SÃO PAULO \\ STATE MUNICIPALITIES
}

\author{
Joyce Stenico', Flávia Domingos Pacheco², Marcos Paulo Marcuz Venier ${ }^{3}$, \\ Marcos José Chagas Cerimarco ${ }^{4}$, Demóstenes Ferreira da Silva Filho5 ${ }^{5}$, Marcelo Machado Leão6.
}

\begin{abstract}
RESUMO
A gestão da arborização urbana é de responsabilidade direta dos municípios, ou seja, as prefeituras são encarregadas pelas avaliações, autorizações, plantio, manejo e supressão dos indivíduos arbóreos. $O$ objetivo do trabalho foi analisar os processos de gestão realizados, bem como a situação da arborização viária de 50 cidades do Estado de São Paulo, por meio de aplicação de questionários via telefônica e por e-mail. Em linhas gerais, os centros urbanos analisados mostraram-se bastante deficientes em relação ao planejamento e ao manejo das árvores nas vias públicas, o que indica a necessidade da administração pública dispensar maior atenção ao tema e aumentar os investimentos na área.
\end{abstract}

Palavras-chave: Floresta urbana; Manejo arbóreo; Administração pública.

\begin{abstract}
Urban forestry is a task to be administered by the City Halls, according to environmental policy instruments. Municipalities are responsible for evaluations, authorizations, planting, management and suppression of trees. The main goal of this study was to analyze the management processes carried out, as well as the current situation of urban forest along the road system of fifty cities located in São Paulo State. It was inferred that those cities do not have sufficient planning, management actions and monitoring of trees in the road system, which means the municipalities need to look into this issue thoroughly and increase the investments, besides implement the use of new technologies to increase quality of urban trees management.
\end{abstract}

Keywords: Urban forest; Tree management; City Halls.

Recebido em 30.05.2019 e aceito em 06.09.2019

1 Gestora Ambiental. Bacharela. Bolsista. FAPESP. Piracicaba/SP. Email: joyce.stenico@gmail.com

2 Gestora Ambiental. Bacharela. Bolsista. FAPESP.Piracicaba/SP. Email: flavia@propark.com.br

3 Gestor Ambiental. Bacharel. ESALQ-USP. Piracicaba/SP. Email: marcosmvenier@gmail.com

4 Analista de Infraestrutura em TI. Bacharel. Bolsista. FAPESP. Piracicaba/SP. Email: mcerimarco@hotmail.com.br

5 Engenheiro Agrônomo. Livre docente. Professor de Silvicultura Urbana. ESALQ-USP. Piracicaba/SP. Email: dfilho@usp.br

6 Engenheiro Agrônomo. Pós-Doutor. Pesquisador. ESALQ-USP. Email: marceloleao@usp.br 


\section{INTRODUÇÃO}

Com a migração para os centros urbanos e o aumento do desenvolvimento das cidades, é cada vez maior a preocupação quanto à manutenção da qualidade de vida neste ambiente (SILVA et al., 2019).

A arborização urbana, quando bem gerenciada, oferece diversos benefícios de ordem social, econômica e ambiental, que proporcionam melhorias ao bem-estar da população. No entanto, a falta de planejamento e de recursos operacionais e humanos, além da fiscalização ineficiente e plantio de espécies inadequadas no sistema viário se tornam empecilhos para se atingir esses proveitos (SOUZA et al., 2011; CARNEIRO; CARVALHO, 2013; SANTOS; LISBOA; CARVALHO, 2012). A arborização urbana de um município não se resume ao plantio de árvores, mas também à valorização e ao respeito, mantendo o planejamento inicial, o manejo adequado e o gerenciamento integrado, por meio de programas, planos e projetos de gestão municipal, com a finalidade de alcançar melhorias para a comunidade (SANTOS et al., 2014; MONTEIRO et al., 2013; SANTOS; LISBOA; CARVALHO, 2012).

Contudo, segundo um estudo realizado Costa (2015), a gestão da floresta urbana nos municípios paulistas apresentam algumas deficiências, incluindo questões políticas, relativas à instrumentos legislativos, estruturais e orçamentários; e questões técnicas, referentes à escolha de espécies, coleta de sementes, poda, remoção, entre outros. Resultando em indivíduos arbóreos incompatíveis e com má formação, não identificação de árvores perigosas e, consequentemente, o aumento dos riscos à população.

Konrad et al. (2016) afirmam também que gestão da arborização em municípios do Estado de São Paulo constitui-se de um tema que ainda precisa ser trabalhado pelos gestores públicos municipais, ou seja, as estratégias precisam ser melhor delineadas para a geração de maiores benefícios associados aos recursos arbóreos.

Nesse contexto, o objetivo deste trabalho foi identificar e avaliar os processos de gestão relacionados à arborização urbana e a sua organização, por meio de pesquisa dirigida, em 50 cidades do Estado de São Paulo - Brasil, a fim demonstrar uma ampla visão de como o planejamento e o manejo de árvores urbanas estão sendo realizados e quais são os pontos positivos e também os entraves que dificultam no processo.

\section{MATERIAL E MÉTODOS}

Com 645 municípios e uma área de 248,23 mil km², o Estado de São Paulo é o estado mais populoso do país, atingindo, em 2019, uma população acima de 44 milhões de habitantes. 
Seu PIB, em 2016, ultrapassou a linha dos 2 trilhões de reais, sendo a participação dos serviços no total do valor adicionado de $76,51 \%$ e $21,41 \%$ da indústria (FUNDAÇÃO SEADE, 2019). No censo de 2010, São Paulo apresentou um percentual de $75,4 \%$ de domicílios particulares permanentes que possuem arborização, ou seja, que apresentam no mínimo uma árvore na via pública em que se insere, conforme dados do Instituto Brasileiro de Geografia e Estatísticas (IBGE, 2010).

Para a realização do presente estudo foram selecionados 50 municípios do Estado de São Paulo, com os seguintes critérios: ser cidade-sede das regiões administrativas ou ter mais de 30 mil habitantes, apresentar mais de $70 \%$ das vias públicas com alguma árvore plantada e serem de diferentes portes, abrangendo assim municípios de diferentes características para representar de forma mais completa o Estado de São Paulo (IBGE, 2010; IBGE, 2017; IGCSP, 2019).

Destaca-se a importância de se considerar, no estudo proposto, municípios de diferentes portes, devido ao grau de influência que exercem na região do entorno e a disparidade apresentadas na sistemática de gestão pública urbana. Os municípios selecionados foram, então, classificados segundo o número de habitantes, de acordo com a categorização de Motta e Mata (2008) da seguinte forma: a) pequeno porte, com menos de 100 mil pessoas; b) médio porte, com população entre 100 mil e 500 mil pessoas e c) grande porte, aqueles com mais de 500 mil habitantes (Quadro 1).

Quadro 1. Classificação dos municípios selecionados para a pesquisa em relação ao seu porte no Estado de São Paulo

Box 1. Classification of the selected municipalities regarding their population size

\begin{tabular}{|l|ll|ll|}
\hline \multicolumn{1}{|c|}{ Grande porte } & \multicolumn{3}{|c|}{ Médio porte } & \multicolumn{2}{c|}{ Pequeno Porte } \\
\hline Campinas & Araçatuba & Marília & Adamantina & Lins \\
Ribeirão Preto & Araraquara & Ourinhos & Avaré & Mogi Mirim \\
Santo André & Assis & Piracicaba & Batatais & Novo Horizonte \\
São Bernardo do Campo & Barretos & Praia Grande & Bebedouro & Registro \\
São José dos Campos & Barueri & Presidente Prudente & Caçapava & Santa Isabel \\
São Paulo & Bauru & Rio Claro & Caieiras & São João da Boa Vista \\
Sorocaba & Birigui & Santos & Garça & São Joaquim da Barra \\
& Botucatu & São Carlos & Jaboticabal & Tietê \\
& Catanduva & São José do Rio Preto & Jales & Votuporanga \\
& Franca & São Vicente & & \\
& Itu & Taubaté & & \\
& Jaú & Várzea Paulista & & \\
& Limeira & &
\end{tabular}


Na figura 1, pode-se observar a distribuição da localização geográfica dos municípios selecionados no Estado de São Paulo para participação na pesquisa.

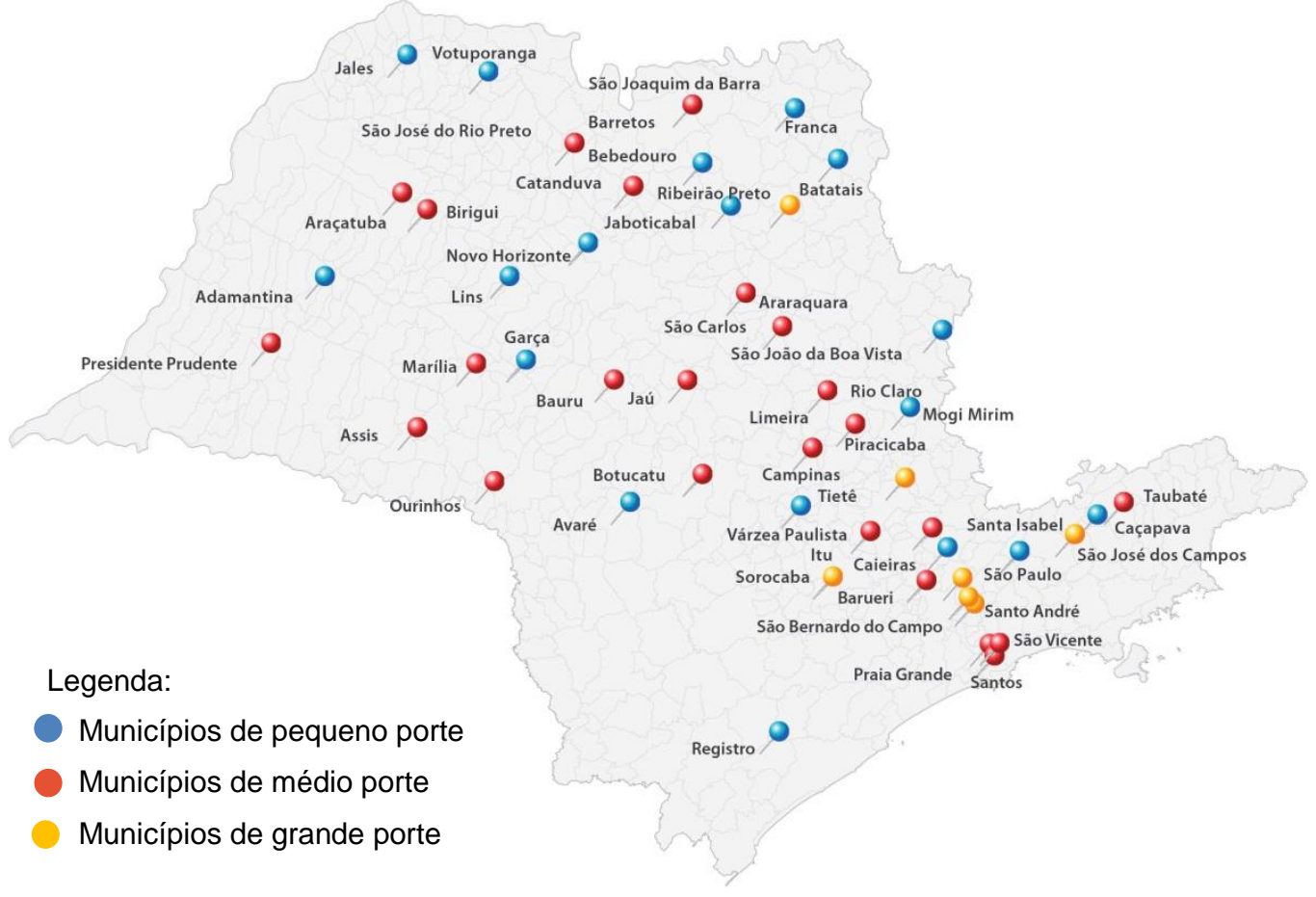

Figura 1. Distribuição geográfica dos municípios do Estado de São Paulo incluídos na pesquisa

Figure 1. Geographic distribution of the municipalities of the state of São Paulo included in the research

Aplicou-se, na sequência, um questionário detalhado, a todas as prefeituras das cidades selecionadas, entre os meses de abril e agosto de 2018, por intermédio de ligações telefônicas e, quando sem retorno ou solicitado pelo responsável, via e-mail.

Os municípios foram questionados com 10 perguntas abertas e dentre os temas foram levantados os seguintes pontos: procedimentos a serem adotados pelo munícipe para solicitar podas ou supressões de árvores em vias públicas; necessidade de elaboração de laudos técnicos e emissão de autorizações para executar o manejo arbóreo pelos servidores municipais.

O questionário incluiu também perguntas sobre 0 tempo estimado para 0 desenvolvimento de cada processo, desde o momento da solicitação do munícipe, incluindo a autorização pelo órgão competente, até o atendimento da demanda inicial. Caracterizou-se o perfil do encarregado pela execução do manejo arbóreo, bem como investigou-se a obrigatoriedade de formação técnica específica do profissional para desenvolver essas atividades.

Procurou-se averiguar ainda se o munícipe arca com algum custo, quando o serviço é realizado pela prefeitura (ou por terceiros por ela contratados) e também, se há possibilidade 
de o manejo ser realizado pelo próprio munícipe; nesse caso, questionou-se se ele recebe orientações para obedecer às normas especificas para a realização do trabalho.

Por fim, foi perguntado aos representantes das prefeituras, se em caso de manejo realizado incorretamente, os profissionais ou munícipes responsáveis por sua execução ficam sujeitos a algum tipo de multa ou sanção.

Os dados foram compilados em planilhas e analisados de acordo com cada tema através de tabelas dinâmicas. Os municípios foram avaliados conjuntamente com o intuito de obter uma ampla visão da gestão da arborização urbana no Estado de São Paulo.

\section{RESULTADOS E DISCUSSÃO}

A Constituição da República Federativa do Brasil (BRASIL, 1988), em seu Artigo n. 23, delega à União, aos estados, aos municípios e ao Distrito Federal a competência para legislar e para proteger o meio ambiente. Ainda nos termos da Constituição e do Estatuto da Cidade (BRASIL, 2001), cabe também ao município criar, preservar e proteger as áreas verdes da cidade e também o sistema de arborização, considerados partes essenciais de sua política de desenvolvimento urbano.

A responsabilidade e atuação dos municípios são empregadas por meio de instrumentos da política ambiental municipal, representados por leis, planos, portarias e outros mecanismos, relacionados à gestão e gerenciamento dos indivíduos arbóreos nas cidades (CEMIG, 2011). A administração municipal precisa apresentar e regulamentar o controle de podas, transplantes, autorizações de supressão de indivíduos arbóreos, regras de compensação, tanto para as árvores existentes em áreas públicas como em áreas privadas, além efetuar o plantio de exemplares nos logradouros públicos (CEMIG, 2011).

Costa (2015) explana em seu estudo que algumas cidades ainda não apresentam nenhum instrumento municipal que regulamenta a gestão da arborização urbana, porém mais de $70 \%$ dos municípios possuem ao menos uma legislação específica para a área.

Assim, considerando que as prefeituras são responsáveis por conservar a vegetação de porte arbóreo ao longo das vias públicas, elas devem implementar e executar os instrumentos da política ambiental para atender às demandas dos munícipes de forma rápida e eficiente.

O contato do munícipe com o responsável pode ser presencial com a ida do interessado até o órgão municipal competente, por via telefônica, ou on-line, por meio de sites e aplicativos disponíveis na internet. 
Nos casos de pedidos de realização de podas (Figura 2), constatou-se que o contato por meio telefônico é aplicado em 18 municípios (36\%). As solicitações on-line têm sido recebidas somente por $18 \%$ das prefeituras.

Os resultados indicaram que a solicitação, na maior parte das vezes, é feita de forma presencial, principalmente quando se trata da remoção de indivíduos arbóreos, onde $80 \%$ das cidades obrigam o munícipe a registrar pessoalmente a sua demanda em algum órgão municipal (Figura 3).

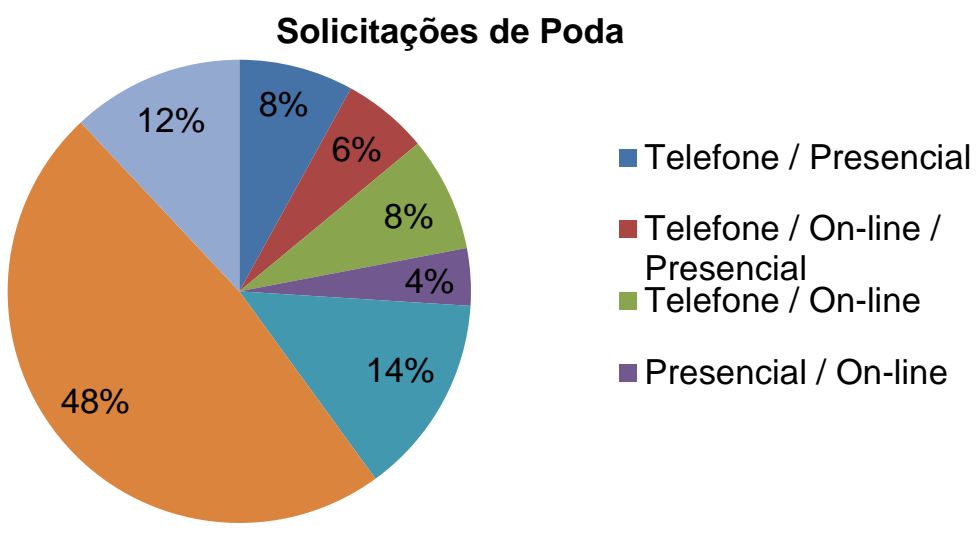

Nota: NA - Não Atende ${ }^{7}$.

Figura 2. Formas utilizadas pelo munícipe para solicitar poda de indivíduos arbóreos nos municípios pesquisados

Figure 2. Methods used by the citizen to request pruning of trees in the surveyed cities

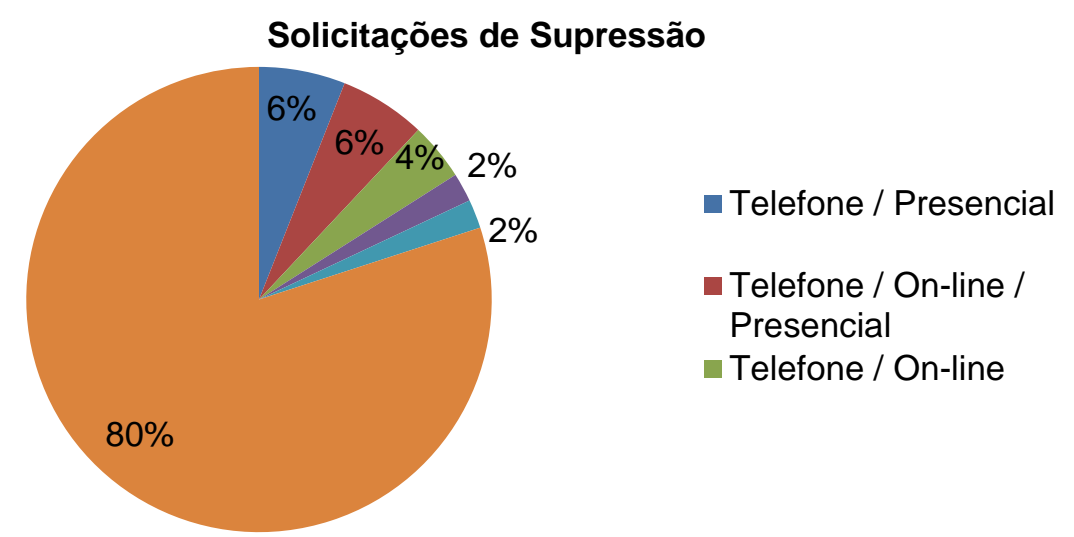

Figura 3. Formas utilizadas pelo munícipe para solicitar supressão de indivíduos arbóreos nos municípios pesquisados

Figure 3. Methods used by the citizen to request suppression of trees in the surveyed cities

Dessa forma, se o cidadão necessitar de autorização ou auxílio do poder público para podar ou remover uma árvore, este deverá entrar em contato com o departamento público responsável pela arborização e registrar a sua demanda. A oportunidade de solicitar os

\footnotetext{
7 Situações em que a solicitação de poda é desnecessária, pois a prefeitura costuma realizar trabalhos periódicos de rotina nos diversos bairros; e/ou o próprio cidadão pode efetuar o manejo sem a necessidade de autorização prévia da municipalidade.
} 
serviços via telefone e internet demonstra alguma preocupação com a acessibilidade e a facilidade no atendimento pela administração pública.

Porém, sabe-se que um sexto das cidades do Estado de São Paulo não dispõe de estrutura específica encarregada pela arborização urbana (COSTA, 2015) e os municípios de médio porte, principalmente, se apresentam ainda resistentes nas opções de disposição dos serviços públicos, dificultando essa comunicação da população com a administração pública.

Nessa questão, observou-se também que, para formalizar o pedido de manejo, o interessado enfrenta um processo burocrático, principalmente, nas cidades que precisam da presença do munícipe no órgão responsável, no qual é necessário informar, por exemplo, os motivos da solicitação, a quantidade e a localização de árvores, além de fornecer os seus dados pessoais (nome, cédula de identidade, cadastro de pessoa física, endereço físico e eletrônico, entre outros).

Pode-se exigir também o fornecimento do nome do proprietário do imóvel, a cópia do documento da sua propriedade (escritura, matrícula em cartório, entre outros), contrato de compra e venda, o carnê do Imposto Predial Territorial Urbano (IPTU) e até mesmo, a assinatura de um Termo de Responsabilidade de riscos e reparação de eventuais danos e prejuízos.

A elaboração de laudo técnico por profissional da prefeitura é obrigatória para todas as solicitações de supressão de árvores urbanas. Em cinco cidades (10\%) a autorização é desnecessária, quando somente os técnicos municipais realizam os serviços de manejo.

Nos casos de pedidos de podas de árvores, 56\% dos municípios não exigem o laudo. Porém, a emissão de autorização do manejo é indispensável em $68 \%$ deles, como se verifica na Figura 4.

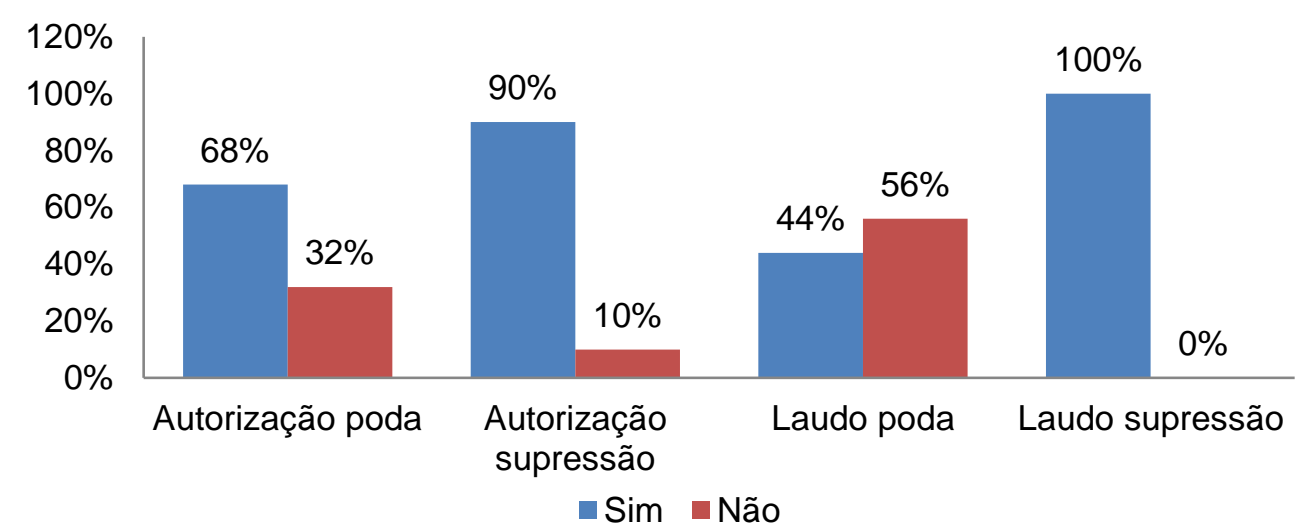

Figura 4. Necessidade de autorização e laudo nos municípios pesquisados

Figure 4. Need for authorization and report in the surveyed cities

A elaboração de laudo técnico de avaliação do estado das árvores e a respectiva autorização para poda e remoção pelos técnicos municipais são mecanismos essenciais para 
avaliar as suas reais condições e os riscos que oferecem pois, muitas vezes, o munícipe ou um contratado não possuem experiência suficiente para definir o manejo mais adequado, sem causar danos irreversíveis aos indivíduos arbóreos.

A obrigatoriedade da realização dos laudos para poda e, principalmente, para supressão, demonstra preocupação da administração pública para o cumprimento da legislação ambiental e para manter o indivíduo arbóreo vivo, já que eles apresentam diversos benefícios para o ambiente. A autorização para o manejo garante um controle das conformidades a serem realizadas pelo profissional.

A realização dos diagnósticos arbóreos pode ser dificultada por diversos fatores: recursos financeiros, disponibilidade de tecnologia e principalmente pela carência de mão de obra, onde $80 \%$ dos municípios apontam a falta de profissionais a maior dificuldade para qualificação da floresta urbana (COSTA, 2015).

O manejo da arborização urbana, para as cidades paulistas pesquisadas, pode ser realizado por funcionários da prefeitura e/ou vinculados a ela (terceirizados), por profissionais contratados pelo requisitante, ou até mesmo pelo próprio munícipe (Figura 5).

Os resultados indicaram que $82 \%$ das prefeituras oferecem os serviços de manejo arbóreo para os munícipes. Os outros $18 \%$ deixam a responsabilidade do manejo e da coleta de resíduos decorrentes das atividades para os solicitantes ou por profissionais por eles contratados. Para Costa (2015), apenas menos de 10\% das cidades não oferecem qualquer manutenção em suas árvores.

Além disso, em dez cidades o cidadão deve pagar à municipalidade pelo trabalho realizado, seja uma taxa de protocolo, o serviço completo ou a compensação ambiental.

Verificou-se que nos 39 municípios que fornecem a alternativa ao cidadão de contratar profissionais para realizarem o manejo arbóreo, 17 prefeituras oferecem uma relação dos profissionais autorizados que podem ser eventualmente contratados para a realização destas atividades.
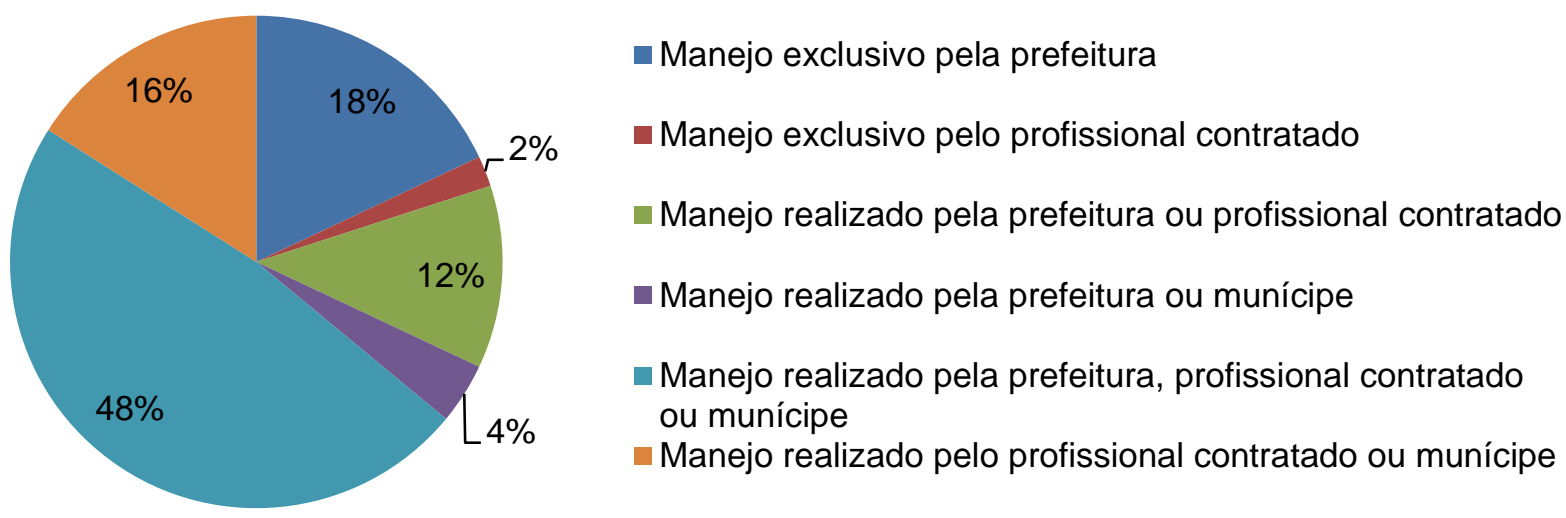

Figura 5. Distribuição do perfil das partes autorizadas a realizar manejo arbóreo em áreas urbanas Figure 5. Distribution of the profile of authorized people regarding tree management in urban areas 
Konrad et al. (2016) reconhecem em seu trabalho a deficiência na qualidade da mão de obra empregada no manejo arbóreo realizado, em especial, para a condução das copas e realização das podas, que são necessárias para reduzir o conflito com equipamentos urbanos.

A falta de oferecimento do manejo da arborização urbana, de capacitação (somente 15 prefeituras oferecem os cursos especializados para formar/capacitar os executores) ou, no mínimo, de uma lista de profissionais capacitados, abre a oportunidade da realização atividades de manutenção da vegetação viária de baixa qualidade.

Se não foram executadas conforme o estabelecido, em $86 \%$ das cidades o proprietário do imóvel pode ser autuado, multado e obrigado a realizar a compensação por meio do plantio de árvores, cuja quantidade depende da gravidade das atividades praticadas e do número de exemplares prejudicados. Em 3 cidades, o munícipe não é diretamente autuado, mas recebe uma notificação e orientações conservacionistas. As demais não possuem fiscalização.

Em relação aos prazos, a emissão de autorização de manejo geralmente ocorrem entre 15 e 30 dias, porém, pode variar de 2 a 60 dias para emissão de autorização de poda e de 2 a 240 dias para supressão.

Nos casos em que a própria prefeitura efetua o manejo, esse período depende da forma como o serviço é realizado; algumas delas executam as podas e supressões por região e/ou bairros e outras atendem as solicitações por ordem de entrada. Nesses casos, o prazo varia entre 15 e 730 dias.

Muitas das prefeituras consultadas adotam uma programação nas atividades relacionadas à arborização urbana, muitas vezes, sem controle e com os recursos alocados ineficientemente, acarretando grande lentidão no atendimento às demandas da população e aumentando os riscos atribuídos à vegetação urbana.

No contexto geral, as cidades ainda enfrentam dificuldades na gestão pública e cabe a elas reavaliar seus processos, favorecendo a vegetação urbana, e atuando para implementar melhorias para uso mais eficaz dos recursos e estruturas disponíveis.

Vale ressaltar que o governo do Estado de São Paulo por meio da coordenação da Secretaria de Estado do Meio Ambiente, auxilia também a implantação de instrumentos da política ambiental municipal, ao conduzir ações do Programa Município Verde e Azul (PMVA) (SÃO PAULO, 2019).

O programa tem o objetivo inovador de medir e apoiar a eficiência da gestão ambiental nas cidades paulistas e promover uma ponte entre os municípios e o Estado, com a intenção de que os municípios criem estrutura própria voltada ao meio ambiente. Além disso, a participação do município no PMVA é um dos critérios de avaliação para a preferência na liberação de recursos do Fundo Estadual de Controle da Poluição (Fecop) (SÃO PAULO, 2019). 
Os critérios de avaliação propostos para cada diretiva do PMVA servem para ranquear os municípios participantes, com o intuito de incentivar a preservação ambiental (LIMA; PIRES; OLIVEIRA, 2015). Durante os anos, houve evolução dos critérios utilizados na diretiva da Arborização Urbana (KONRAD; COSTA; CASTILHO, 2013), que, por sua vez, demonstra a preocupação do Estado com a área.

Porém, apesar da importância de indicadores de sustentabilidade urbana, sua aplicação encontra dificuldades em diversos municípios que não possuem um orgão ambiental responsável ou gestores públicos comprometidos com as causas ambientais (SARUBBI; MORAES; 2018).

\section{CONCLUSÕES}

A pesquisa mostrou que, em linhas gerais, o planejamento e o manejo das árvores nas vias públicas são bastante deficientes nos cinquenta municípios estudados. Apesar de algumas cidades utilizarem recursos para facilitar o processo e agilizar o manejo da arborização urbana com o intuito reduzir os riscos associados à vegetação, a maioria ainda enfrenta entraves burocráticos, que prejudicam a eficiência do atendimento.

Assim, é preciso que as prefeituras obtenham órgãos responsáveis específicos para a área de arborização urbana, disponibilizem recursos humanos e financeiros adequadamente e adotem processos mais modernos e simplificados, tornando-os mais acessíveis e de rápida execução.

Também de essencial importância é a contratação de mais mão de obra especializada, por parte da administração pública, para a emissão de laudos técnicos e autorizações, a fim de fundamentar as análises e respostas quanto às solicitações de manejo e reduzir a concentração de tarefas dos profissionais atuantes.

Ao não oferecer serviços de manutenção da arborização urbana ou realizar contratação de serviços de má qualidade, as prefeituras também deveriam oferecer cursos de capacitação com treinamento sistemático para que os serviços sejam executados adequadamente, principalmente, no caso da responsabilidade pela execução do manejo seja do munícipe, ou por terceiro contratado por ele.

Por fim, as cinquenta prefeituras do Estado de São Paulo pesquisadas se mostraram preocupadas com a arborização urbana, porém, afirmam que os recursos são escassos e os processos lentos. Portanto, é preciso investir em aperfeiçoamento do sistema de gestão e em estratégias para manter a fiscalização e o manejo sempre atualizados, evitando prejuízos e eventuais acidentes decorrentes da falta de manutenção das árvores. 


\section{AGRADECIMENTOS}

Fundação de Apoio à Pesquisa (FAPESP), pelo financiamento da pesquisa por meio do Programa Inovativo na Pequena Empresa - PIPE.

\section{REFERÊNCIAS}

BRASIL. Constituição (1988). Constituição da República Federativa do Brasil. Brasília. 1988. Disponível em: <http://www.planalto.gov.br/ccivil_03/constituicao/constituicao.htm> Acesso em: 20 dez. 2018.

BRASIL. Lei no10.257, de 10 de julho de 2001. Estatuto da Cidade. Brasilia. 2001. Disponível em: <http://www.planalto.gov.br/ccivil_03/leis/leis_2001/l10257.htm>. Acesso: 20 dez. 2018

CARNEIRO D. C.; CARVALHO, S. M. As estruturas de gestão e planejamento da arborização urbana de Ponta Grossa - PR. Periódico Técnico e Científico Cidades Verdes, Tupã, v. 1, n. 1, p. 94-116, 2013.

COMPANHIA ENERGÉTICA DE MINAS GERAIS - CEMIG. Manual de Arborização. Belo Horizonte: CEMIG, 2011.

COSTA, C. M. N. Gestão da arborização urbana no Estado de São Paulo. Piracicaba. 2015. 169p. Dissertação (Mestrado em Ciências). Escola Superior de Agricultura "Luiz de Queiroz" da Universidade de São Paulo, Piracicaba, 2015.

FUNDAÇÃO SEADE. Perfil dos Municípios Paulistas. Disponível em: <http://www.perfil.seade.gov.br/>. Acesso em: 29 ago. 2019.

INSTITUTO BRASILEIRO DE GEOGRAFIA E ESTATÍSTICA - IBGE. Domicílios particulares permanentes e moradores em domicílios particulares permanentes, por condição de ocupação do domicílio, segundo as características do entorno nos municípios de São Paulo. 2010. Disponível em: <ftp://ftp.ibge.gov.br/Censos/Censo_Demografico_2010/ Entorno_dos_Domicilios/xls/Municipios/sao_paulo.zip>. Acesso em: 07 jan. 2019

INSTITUTO BRASILEIRO DE GEOGRAFIA E ESTATÍSTICA - IBGE. Estimativas da população residente no Brasil e unidades da federação com data de referência em $1^{\circ}$ de julho de 2017. 2017. Disponível em: <ftp://ftp.ibge.gov.br/Estimativas_de_Populacao/Estimativas_2017/ estimativa_dou_2017.pdf>. Acesso em: 7 jan. 2019.

INSTITUTO GEOGRÁFICO E CARTOGRÁFICO DE SÃO Paulo - IGCSP. Mapas Individuais das RAs e Metropolitanas. Disponível em: < http://www.igc.sp.gov.br/produtos/mapas_ra. aspx>. Acesso em: 07 jan. 2019

KONRAD, E. G.; COSTA, S.M.A.L.; SABBAG, O.J.; CASTILHO, R.M. Gestão da arborização urbana em municípios do estado de São Paulo. Revista ESPACIOS. Caracas, v. 37, n. 22, p. 9. 2016.

KONRAD, E. C. G.; COSTA, S. M. A. L.; CASTILHO, R. M. M. O programa município verdeazul e a arborização urbana. Revista da Sociedade Brasileira de Arborização Urbana. Curitiba. v. 8, n. 4, p. 59-72, 2013.

LIMA, M. M.; PIRES L. F.; OLIVEIRA, J.B. Gestão ambiental compartilhada: o Programa 
Município Verde Azul. Periódico Eletrônico Fórum Ambiental da Alta Paulista, Tupã, v. 11, n. 7, p. 133-138, 2015.

MONTEIRO, M. M. G.; TETTO, A. F.; BIONDI, D.; SILVA, R. R. de S. Percepção dos usuários em relação à arborização da avenida Cândido de Abreu - Curitiba - PR. Revista da Sociedade Brasileira de Arborização Urbana. Curitiba. v. 8, n. 2, p. 20-34, 2013.

MOTTA, D.; MATA, D. da. Crescimento das cidades médias. IPEA. 2008. Disponível em: <http://www.ipea.gov.br/agencia/images/stories/PDFs/boletim_regional/081207_boletimregional 1_cap6.pdf>. Acesso em: 20 dez. 2018.

SÃO PAULO. Governo de SP auxilia cidades nas questões ligadas à gestão ambiental. Disponível em: <http://www.saopaulo.sp.gov.br/ultimas-noticias/governo-de-sp-auxilia-cidadesnas-questoes-ligadas-a-gestao-ambiental/>. Acesso em: 30 ago. 2019.

SANTOS, R. C.; BESSEGATTO, D.; ANTUNES, L.; MALENGO, F. de M. Análise qualiquantitativa da arborização urbana do centro da cidade de Sananduva-RS. Revista Gestão \& Sustentabilidade Ambiental. Florianópolis. v. 7, n. 2, p. 143-158, 2018.

SANTOS, T. O. B. dos; LISBOA, C. M. C. A.; CARVALHO, F. G. de. Análise da arborização viária do bairro de Petrópolis, Natal, RN: uma abordagem para diagnóstico e planejamento da flora urbana. Revista da Sociedade Brasileira de Arborização Urbana, Curitiba, v. 7, n. 4, p. 90-106, 2012.

SARUBBI, M. P.; MORAES, C.S.B. Avaliação comparativa de metodologias de indicadores para a sustentabilidade urbana. Cadernos Zygmunt Bauman, São Luís, v. 8, n. 18, p.211$231,2018$.

SILVA, O. H.; LOCASTRO, J. K.; SANCHES, S. da P.; DE ANGELIS NETO, G.; DE ANGELIS, B. L. D.; CAXAMBU; M. G. Avaliação da arborização viária da cidade de São Tomé, Paraná. Ciência Florestal, Santa Maria, v. 29, n. 1, p. 371-384, 2019.

SOUZA, A. L.; FERREIRA, R.A; MELLO, A. A. de; PLÁCIDO, D. R.; SANTOS, C. Z. A. dos; GRAÇA, D. A. S. da; ALMEIDA JÚNIOR, P.P de; DANTAS, J. D. de M.; PAULA, J. W. A. de; SILVA, T. L. da; GOMEs, L. P. S. Diagnóstico quantitativo e qualitativo da arborização das praças de Aracaju, SE. Revista Árvore, Viçosa, v. 35, n. 6, p. 1253-1263, 2011. 